\title{
O ESPAÇO SOCIAL DA MÚSICA NA FORMAÇÃO DAS UNIVERSIDADES DO SÉCULO
} XIII

Patrícia L.L. Mertzig Goncalves de Oliveira, Luciana Carolina Fernandes de Faria, Emmanuel Fernandes da Costa Ramalho

Universidade do Oeste Paulista - UNOESTE, Faculdade de Arte, Ciências, Letras e Educação de Presidente Prudente, Presidente Prudente, SP. E-mail: patriciamertzig@gmail.com

\section{RESUMO}

A Música foi encarada, durante toda a Idade Média, como área de conhecimento e pertencente ao Quadrivium, a mais alta divisão das Artes Liberais. Nesse período muitos tratados musicais foram escritos sob influência da Grécia Antiga principalmente de filósofos como Pitágoras, Platão e Aristóteles. No século XIII, com a formação das cidades e o surgimento das Universidades, o ensino de música manteve-se no Quadrivium junto com outros conhecimentos ligados à matemática. No presente artigo, por meio de abordagem teórica, descrevemos o espaço social que a música se encontrava no contexto da formação das universidades e traçar possíveis paralelos com o ensino de música na atualidade nas universidades brasileiras. Verificamos que atualmente há uma valorização da música instrumental destacando a performance dos músicos, como influência das mudanças sociais da música ocorridas na Idade Moderna, se distanciando assim da função social que possuía nas Universidades no século XIII.

Palavras-chave: Música, Universidade, Idade Média, Século XIII.

\section{THE SOCIAL SPACE OF MUSIC IN THE FORMATION OF UNIVERSITIES IN THE THIRTEENTH CENTURY}

\begin{abstract}
Music was, throughout the Middle Ages, regarded as an area of knowledge and belonging to the Quadrivium, the highest division of the Liberal Arts. During this period many musical treatises were written under the influence of Ancient Greece mainly of philosophers like Pythagoras, Plato and Aristotle. In the thirteenth century, with the formation of cities and the emergence of Universities, the teaching of music remained in Quadrivium along with other knowledge related to mathematics. In this article, through a theoretical approach, we describe the social space that the music was in the context of the formation of the universities and draw possible parallels with the teaching of music in the Brazilian universities. We verified that there is currently an appreciation of instrumental music highlighting the performance of musicians as an influence of the social changes of music occurred in the Modern Age thus distancing itself from the social function it had in universities in the thirteenth century.
\end{abstract}

Key-words: Music, University, Middle Ages, XIIIth Century.

\section{INTRODUÇÃO}

Atualmente, é comum pensarmos em música como uma forma de Arte. Além dela, temos também outras formas de expressão artística como o teatro, a dança, as artes visuais, a literatura e 
a arquitetura. Existem também outras, mais contemporâneas, como o cinema e a fotografia, além do circo que a comunidade artística tem mostrado uma tendência em aceita-lo no hall das Artes. Com o advento das novas tecnologias de informação e comunicação, o que se observa é uma produção artística híbrida, abstrata, reflexiva e um tanto quanto distante de grande parte da população.

Saber o que nossa sociedade atual entende por Arte é de suma importância para compreendermos tal discussão, pois as concepções a respeito da Arte, bem como sua função social, variaram muito na história do Ocidente. A música não pertencia à mesma categoria que as artes visuais e cênicas na Idade Antiga, na Idade Média e em parte da Moderna. Na Idade Média, a música fazia parte do Quadrivium compondo as chamadas Artes Liberais, juntamente com a aritmética, a geometria e a astronomia. Tal divisão não compreendia a pintura, a escultura, nem o teatro. O valor dado a cada uma dessas expressões artísticas é fator relevante para compreender o papel social que cada uma cumpriu na Idade Média. Também, a distância que houve entre música e artes visuais, por exemplo, resultou em formas bastante distintas de se ensinar e aprender sobre elas. Essa divisão de funções colocou a música no contexto das Universidades no século XIII, e assim, integrando as sete artes liberais, a música apresentou um rico desenvolvimento de ordem intelectual que culminou na escrita musical e no advento da polifonia.

Além de fazer parte de conteúdos universitários, no período em questão, a música estava presente nas igrejas com o canto litúrgico e também nas ruas com a prática itinerante de trovadores, jograis e menestréis. No século XIII, com a formação das cidades, a música dita profana podia ser observada em diferentes estilos como as canções de gesta, cancioneiros, no amor cortes, Cantigas de Santa Maria, entre outras. Ou seja, o período, tal como podemos observar também na atualidade, divide a música em duas vertentes: aquela teórica, formativa e universitária e a outra, prática, funcional e pública.

Atualmente, assim como as artes visuais e outras modalidades artísticas, a música ocupa nas universidades o espaço dos cursos de graduação. No Brasil, as universidades que oferecem a graduação em músicas apresentam conteúdos e metodologias bem distintas das apresentadas pelas universidades medievais. No Estado de São Paulo, por exemplo, a Universidade de São Paulo (USP), a Universidade de Campinas (UNICAMP) e a Universidade Estadual Paulista (UNESP) mantém orquestras, grupos de câmara e Big Bands que independem, executiva ou funcionalmente, do curso de graduação. Nesse contexto é possível observar uma música prática, voltada ao público, e outra teórica, ensinada nos cursos de graduação.

Alguns cursos oferecem bacharelados em instrumentos musicais, em composição e regência e outros ofertam a licenciatura em música. Além destes, a UNICAMP, por exemplo, separou seu bacharelado em instrumento em duas vertentes: a que estudada a música erudita e a que estuda a música popular.

Assim como nas Universidades medievais no século XIII, podemos perceber que a função social da música nas Universidades brasileiras apresenta duas facetas distintas: há uma música prática, executada, apreciada pela população, e outra que apresenta um corpo teórico mais aprofundado, visando à formação de estudantes que, como futuros profissionais, atuarão em diversos segmentos musicais (grupos instrumentais, igrejas, projetos sociais, culturais, espetáculos, escolas de música, conservatórios, escolas públicas e particulares de ensino básico e universidades).

Nesse sentido, observar o surgimento do espaço ocupado pela música na universidade medieval e sua importância no processo formativo de uma sociedade, é imprescindível para compreender o espaço ocupado por ela na sociedade atual. Esta reflexão permite assim observar pontos que coincidem e que divergem na educação atual e como é possível evoluir a partir da observação do comportamento social e mental passado. 


\section{METODOLOGIA}

A revisão bibliográfica, segundo Severino (1996), apresenta caráter político, isto é, a pesquisa deve sempre objetivar a contribuição para a transformação de uma realidade, demonstrando o envolvimento dos pesquisadores com a problemática estudada. Para tanto, foi realizado um levantamento bibliográfico a fim de observar, analisar e descrever o espaço da música na formação das universidades europeias no século XIII, abordando o contexto social e o papel da música na sociedade em questão.

\section{RESULTADOS}

A concepção de música na Idade Média, embora tenha traços da música hebraica por conta do cristianismo primitivo, é uma herança direta da cultura que deu origem a civilização Ocidental: a greco-romana. Para os gregos a palavra Arte vem de Ars que significa "atividade humana com regras". Assim sendo todos os ofícios humanos levavam o nome de arte. Sendo muito abrangente o conceito de arte, diferentes filósofos tais como Platão (428-348 a.C.), Aristóteles (384-322 a.C.) e Plotino (205-270 a.C.) se ocuparam em dividir as artes de acordo com sua finalidade, necessidade ou ainda a ação envolvida para realizar a atividade. De acordo com Chauí (1999, p. 317)

Uma obra, As núpcias de Mercúrio e Filologia, escrita pelo historiador romano Varrão, oferece a classificação que perdurará do século II d.C. ao século XV, dividindo as artes em liberais (ou dignas do homem livre) e servis ou mecânicas (próprias do trabalhador manual).

As artes mecânicas eram ligadas aos trabalhos manuais como, por exemplo, a escultura, pintura, agronomia, medicina, artesanato, etc., e as artes liberais, por outro lado, designavam as atividades ligadas a Sapiência: gramática, retórica, lógica aritmética, geometria, astronomia e música. Isso porque a música e a relação entre os sons foi proposta por Pitágoras, no século VI a.C., que buscava entendê-la segundo suas relações numéricas e não como fenômeno sonoro propriamente dito. De acordo com o verbete "Pitágoras" da Enciclopédia Plêiade

[...] Pitágoras verificou que o som é produzido graças ao movimento do ar que é tanto mais agudo quanto mais rápido é esse movimento. Não chegou, no entanto, a conceber a teoria das vibrações, e, ainda que o tivesse conseguido, não teria sabido como avalia-las. O filósofo descobriu também que duas cordas da mesma espessura e igualmente tensas dão o intervalo de oitava se uma (a mais aguda) medir metade da outra; o intervalo de quinta (dosol), se os respectivos comprimentos estão na razão de 2 pra 3; o intervalo de quarta (do-fa), se os comprimentos estão como 3 para 4. Em conclusão, todas estas relações estão contidas no quaternário 1-2-3-4. (Apud TOMÁS, 2002 p. 23).

Destarte, é possível compreender a posição da música nas artes liberais, pois, assim como a astronomia, a descoberta pitagórica coloca a relação dos sons com suas escalas, harmonias, ritmos e a própria confecção dos instrumentos musicais subordinados às leis físicas de acústica e à lógica matemática. Por outro lado, é importante ressaltar também que, para os gregos da antiguidade, a música era responsável por educar a alma, da mesma forma que a ginástica por educar o corpo.

A importância da música e da educação musical pode ser observada em diferentes textos filosóficos produzidos no período. Platão (2002) em sua obra A República apresenta a importância da música na formação dos guardiões e aborda, de forma detalhada, a relação da música como 
mantenedora do ethos grego. Ele descreve quais instrumentos musicais devem ser utilizados e quais devem ser evitados, quais modos gregos são mais adequados, e ainda versa sobre harmonia, ritmo e da ligação entre música e poesia.

Para Platão (2002), a música está também intimamente ligada à formação do caráter. De acordo com os preceitos gregos o bom caráter depende do equilíbrio, da temperança. Assim, o autor discorre sobre os vícios que devem ser evitados e as virtudes que devem ser valorizadas na formação dos guardiões em seu ideal de cidade. À música cabe educar a alma e despertar nos cidadãos a simplicidade.

Assim, o bom discurso, a boa harmonia, a graça e a eurritmia dependem da simplicidade do caráter, não dessa tolice a que denominamos amavelmente simplicidade, mas da simplicidade autêntica de um espírito que alie a bondade à beleza (PLATÂO, 2002 p. 107).

Apesar de a música ter uma ligação metafísica na formação do homem grego, ela se apresenta como uma área de estudo da matemática. Desde Pitágoras, a música é associada ao movimento dos planetas, surgindo assim a Teoria das Esferas, que apresenta as escalas musicais com uma corresponde numérica na movimentação dos planetas. Essa perfeição numérica previsível e constante foi, para os gregos, a máxima expressão da perfeição da natureza.

Esse paradigma alcançou a Idade Média. Agostinho (354-430 d.C.), bispo de Hipona, escreveu um importante tratado chamado De Musica. Nessa obra o filósofo reconhece a música como fruto da razão e com aplicação da matemática de acordo com os preceitos pitagóricos. Para Agostinho a música é ligada à poesia, e seu tratado apresenta não só uma tendência neoplatônica da música com sua função reguladora da moral, mas também aborda o ritmo, a melodia, o metro, o verso e os modos para composição musical.

O tratado De Musica, escrito em seis livros na forma de um diálogo entre um discípulo e seu mestre tem como eixo central a ascensão ao conhecimento de Deus e Sua presença no mundo pela música. Agostinho elabora considerações a esse respeito de forma aparentemente técnica, nos cinco primeiros livros, nos quais transmite conhecimentos técnicos sobre o ritmo, o metro e o verso, e culmina no sexto livro com a concepção de Deus. (FUCCI AMATO, 2005 p. 21)

Além de Agostinho outros filósofos medievais também escreveram tratados sobre música como Boécio (480-524), Cassiodoro (490-581) e Isidoro de Sevilha (560-636). Todos apresentam forte influência neoplatônica e neopitagórica, porém suas teorias se adequam perfeitamente ao caráter cristão. "Eles representam o final da antiga ciência musical do Ocidente. Com eles inicia-se a teoria e a ciência medieval da música" (FONTERRADA, 2008 p. 33).

Boécio foi figura importante para a manutenção da música na formação das Universidades no século XIII, pois seu tratado De institutione musica foi bastante utilizado e Boécio foi considerado o tradutor da música dos gregos para a escolástica. Sua abordagem é a mesma de Pitágoras que vê a música como teoria matemática, mas, assim como outros medievalistas, acredita que a música colabora na ascensão divina.

Se outros tratados já apresentam a música em suas especificidades (melodia, ritmo, harmonia, instrumentos) o de Boécio é mais detalhado ainda. Nele, o filósofo apresenta a música e sua relação matemática, a teoria dos sons (aspectos acústicos e harmônicos), aspectos da audição, discorre sobre a performance musical, a educação musical, relações intervalares, formação de tetracordes, consonância e dissonância, e o prazer de ouvir. Para tanto, o autor divide seu tratado 
em musica mundana, musica humana e musica constituta in instrumentos, porém é categórico em relação a valorização da teoria da música em relação a música executada. De acordo com Castanheira (2009, p. 10/11)

Boécio afirma que o músico não é aquele que toca um instrumento ou escreve canções, mas aquele que domina e aplica os princípios especulativos da disciplina. $O$ estudo racional é considerado mais importante do que a performance e não depende desta. Apenas a razão dá a habilidade para julgar o que é apropriado e o que não é, podendo identificar boas e más influências da música e controlá-las.

É possível observar que existia uma diferença entre os músicos e os que escrevem ou buscam compreender a teoria da música. A música vai para o contexto das universidades no século XIII porque ela pertence ao Quadrivium. Nesse sentido, ela é compreendida por sua relação direta com a matemática e assim fica claro compreender porque o tratado de Boécio foi bastante utilizado no período. As traduções, nesse sentido, de importantes textos gregos, como os tratados de lógica de Aristóteles, feitas por Boécio, bem como seu tratado De institutione musica, contribuíram não só para o conhecimento musical, mas também para todos os saberes das Artes Liberais.

O grande movimento das traduções latinas que se estendeu durante aproximadamente duas gerações (1130-1190), é um dos fenômenos culturais mais importantes do século XII, ainda mais significativo por se tratado de um trabalho organizado, com equipes de tradutores, de financiadores de traduções e uma verdadeira rede de divulgação das mesmas (VERGER, 2001 p. 70).

Quando Boécio afirma que a música teórica é mais importante que a prática, está separando a execução musical do ambiente acadêmico e justificando sua presença ao lado da aritmética, geometria, astronomia. Assim, a música não se encontra no mesmo patamar das outras artes, pois possuem funções sociais completamente distintas.

\section{DISCUSSÃO}

Em função do que foi exposto, a música dita teórica não é compreendida como expressão artística junto com as outras modalidades. Porém sua prática existia nas Igrejas, nas ruas, nos palácios, no cotidiano cortês. Aqui é possível questionarmos porque a música ensinada nas universidades no século XIII não abordava conhecimentos de ordem prática como a performance instrumental. A separação da música prática do ambiente universitário faz com que todo o conhecimento teórico musical não fosse acessível ao músico performático. Nesse aspecto, a música no espaço universitário atual é bem diferente, pois os cursos de graduação, independentes de bacharelados ou licenciaturas, são pensados para incentivar a prática musical. Isso ocorre porque a prática social da música na atualidade mantém como modelo a valorização da performance desenvolvida na Idade Moderna e início da Contemporânea alcançando seu ápice no Romantismo do século XIX.

Tratando agora da música medieval prática, tocada e cantada, é claramente dividida: a profana e a sacra. Com a formação de uma sociedade cortesã, tanto a música quanto a literatura deixaram de permanecer sob tutela da igreja, tornando-se possível criar relações entre o ouvinte e o músico e a valorização deste na sociedade. 
Com a chegada da Idade Moderna a música caminha para ocupar um espaço cada vez mais significativo fora das igrejas. Além do canto litúrgico praticado e ensinado na igreja, a nova forma de pensar racionalmente impulsionou a música a se apresentar com novas formações instrumentais.

As diferentes concepções estéticas vividas na Modernidade são, na história da música, convencionalmente divididas em Renascimento (século XVI), Barroco (século XVII) e Classicismo (século XVIII). A escrita musical e novas técnicas de composição favoreceram inúmeras formações instrumentais e o ouvinte passou a participar mais ativamente destas inovações. Se antes a música sacra tinha um caráter mais ritualístico e a música profana enfatizava a letra das canções, agora ela deixa de ser subordinada a letra e o público se deleita com os diferentes timbres e nuances da melodia. Mais do que isso: o público passa a compreendê-la.

O desenvolvimento científico também colabora, por meio do conhecimento físico e acústico, na confecção dos instrumentos musicais. Os instrumentos passam a ser compreendidos a partir de sua relação física e agrupados em famílias. O século XVII reconhece a função dos luthiers como, por exemplo, Antonio Stradivárius (1644-1737). Violino, viola e violoncelo são bastante semelhantes na sua construção e na forma de produzir o som (uso do arco), diferindo apenas em seu tamanho e, portanto em seu timbre. Isso só foi possível graças à liberdade de se pensar cientificamente aplicar os avanços tecnológicos na confecção de instrumentos.

A música somente se uniu ao que hoje chamamos de Arte já na Idade Moderna, mais especificamente no século XVII, quando a sociedade apresenta uma nova concepção estética e define a produção artística como Belas-Artes, pois sua única função é ser bela. Ora, outra arte para uma sociedade já bem distinta da medieval.

A distinção entre artes da utilidade e artes da beleza acarretou uma separação entre técnica (o útil) e arte (o Belo), levando à imagem da arte como ação individual espontânea, vinda da sensibilidade e da fantasia do artista como gênio criador. Enquanto o técnico é visto como aplicador de regras e receitas vindas da tradição ou da ciência, o artista é visto como datado de inspiração, entendida como uma espécie de iluminação interior e espiritual misteriosa, que leva o gênio a criar a obra (CHAUÍ, 1999 p. 318, grifo da autora).

O século XIX é, na história da Música, designado como Romantismo ou Período Romântico. Aqui o gênio criador citado acima já é entendido como o suprassumo musical; o ego, as dores e amores dos compositores são postos em evidência e seu humor e estados d'álma influenciam diretamente nas composições musicais. Esteticamente a arte musical já se apresenta bem distinta do período anterior e a relação com o público também não é mais a mesma.

\section{CONCLUSÃO}

Atualmente já não nos referimos à música ou outras modalidades artísticas como BelasArtes, por não considerarmos as diferentes áreas do conhecimento humano e os diferentes ofícios como Arte. Nas universidades brasileiras atuais os departamentos de Arte apresentam graduações em artes visuais, em sua maioria, música, e algumas instituições oferecem teatro, dança e design em nível de graduação. São áreas de conhecimento específicas e centradas em sua produção, execução e educação para o ensino de arte. A música, assim, já não pertence mais ao conjunto de saberes denominado Artes Liberais, nem se une mais à aritmética, geometria e astronomia e sim às áreas de conhecimento que denominamos por Arte e valorizam a performance pela influência da visão romântica valorizando a afetividades e as emoções, o grande legado do período. 


\section{REFERÊNCIAS}

CASTANHEIRA, C.P. De Instituione Musica, de Boécio: Livro 1 tradução e comentários. 2009. $154 f$. Dissertação (Mestrado em Estudos Literários) Faculdade de Letras, Universidade Federal de Minas Gerais. Belo Horizonte, Disponível em: http://www.bibliotecadigital.ufmg.br/dspace/bitstream/handle/1843/ECAP7QRGC9/disserta_o_completo.pdf?sequence=1. Acesso em: 02 nov. 2016.

CHAUÍ, M. Convite à filosofia. São Paulo: Ática, 1999.

FONTERRADA, M.T.O. De tramas e fios: um ensaio sobre música e educação. $2^{\circ}$ ed. São Paulo: Editora UNESP; Rio de Janeiro: Funarte, 2008.

FUCCI AMATO. R.C. A música em Santo Agostinho. Em Pauta: Revista do Programa de PósGraduação em Música da Universidade Federal do Rio Grande do Sul (UFRGS), Porto Alegre, v. 16, n. 26, p.19-35, 2005.

PLATÃO. A República. Trad. Enrico Corvisieri. São Paulo: Editora Best Seller, 2002.

SEVERINO, A. J. Metodologia do trabalho científico. 20 ed. rev. e ampl. São Paulo: Cortez, 1996.

TOMÁS. L. Ouvir o logus: música e filosofia. São Paulo: Editora UNESP, 2002.

VERGER. J. Cultura, ensino e sociedade no Ocidente nos séculos XII e XIII. Trad. Viviane Ribeiro. Bauru, SP: EDUSC, 2001. 